\title{
Study of Ion Mobility Characteristics and Morphology of some Electrochemically- Synthesised Polypyrroles
}

\author{
Danesh Roudini ${ }^{1}$, Peter J. S. Foot ${ }^{2}$ \\ School of Life Sciences, Pharmacy \& Chemistry, Kingston University London, Kingston upon Thames, U.K ${ }^{1,2}$
}

\begin{abstract}
This paper reports the diffusion coefficients of various dopant counter-anions into electro synthesised polypyrrole films, the cyclic voltammetry behaviour of the doped polymers and the effects of the electrolyte on the morphology of the polymer. The diffusion properties of electrochemically-prepared poly (N-dodecylpyrrole) and polypyrrole films were investigated in electrochemical cells containinglithium perchlorate, tetra methyl ammonium chloride and sodium dodecyl benzene sulfonate, and the effects of the size of the ions on their diffusion coefficients are discussed.
\end{abstract}

Keywords: Polypyrrole, Cyclic Voltammetry, Dopant Diffusion.

\section{INTRODUCTION}

Among conducting polymers, polypyrrole is one of the For small potential changes, a plot of $\left(E_{t}-E_{0}\right)$ versus most extensively studied because the monomer (pyrrole) is $t^{-1 / 2}$ follows a straight line of slope $\mathrm{S}$, given by: easily oxidized, water-soluble and commercially available. Polypyrrole presents several advantages including environmental stability, good redox properties and the ability to give high electrical conductivities. Since pyrrole has a relatively low oxidation potential, electro polymerisation can be carried out in aqueous electrolytes, which is not possible for thiophene or benzene [1-3].

The ion exchange behaviour during the charging and discharging processes of conducting polymer electrodes has been investigated in recent years $[4,5]$. The kinetics depends on many factors such as polymerisation conditions $[4,6]$ and the type and size of the counter-ions incorporated during the polymerisation process. In addition, the thickness of the polymer film has a remarkably large effect on the ion exchange [7].

The diffusion of dopants into conducting polymers can be measured electrochemically. The transport of ions into or out of a film can be followed by passing a short current pulse to create an excess of dopant counter-ionsat the surface of a film immersed in an electrolyte solution. By following the relaxation of the surface potential as the concentration of counter-ions returns to equilibrium throughout the polymer, it is possible to determine the diffusion kinetics. A plot of working electrode potential versus $(1 / \sqrt{ }$ time $)$ has a linear region; its slope can be used to calculate the diffusion coefficient [8].

During the equilibration, a plot of electrode potential, E, against $\mathrm{t}^{-1 / 2}$ should follow a straight line if the diffusion behaviour is governed by Fick's law. As a convention, if the polymer electrode is made more positive, the process would be called 'doping' and the potential becomes more negative in 'dedoping'. The following expression is used for the estimation of the diffusion coefficient for the ions into and out of the electrode material:

$$
\exp ^{\frac{\left(E_{t}-E_{0}\right) F}{R T}}-1=\frac{I P}{(1-y) F A C} \sqrt{\pi D t}
$$

$$
\mathrm{S}=\frac{\mathrm{IPRT}}{(1-\mathrm{y}) \mathrm{F}^{2} \mathrm{AC} 0 \sqrt{\pi \mathrm{D}}}
$$

from which:

$$
\mathrm{D}=\frac{\mathrm{I}^{2} \mathrm{P}^{2} \mathrm{R}^{2} \mathrm{~T}^{2}}{(1-\mathrm{y})^{2} \mathrm{~F}^{4} \mathrm{~A}^{2} \mathrm{C}_{0}^{2} \mathrm{~S}^{2} \pi}\left(\mathrm{cm}^{2} \mathrm{~s}^{-1}\right)
$$

where $\mathrm{I}$ is the strength of the current pulse (A), $\mathrm{P}$ is the duration of the pulse (s), $\mathrm{R}$ is the universal gas constant $\left(8.314 \mathrm{~J} \mathrm{~mol}^{-1} \mathrm{~K}^{-1}\right), \mathrm{T}$ is the experimental temperature $(\mathrm{K}), \mathrm{F}$ is Faraday's constant $\left(96487 \mathrm{C} \mathrm{mol}^{-1}\right)$, $\mathrm{A}$ is the area of the polymer coated electrode $\left(\mathrm{cm}^{2}\right), \mathrm{C}_{0}$ is the dopant concentration in the polymer film $\left(\mathrm{molcm}^{-3}\right)$, $(1-y)$ is the concentration correction factor and $E_{0}$ is the final equilibrium potential of the electrode [9].

This method is preferred because, while measuring diffusion, no current is applied through the electrode material. As a result, no correction has to be made for electron transfer kinetics or variable ohmic (IR) potential differences.

\section{EXPERIMENTAL}

\section{A. Materials and Apparatus}

Pyrrole 98\% (Sigma Aldrich), used for the synthesis of PPy films, was purified by distillation over calcium hydride under vacuum and stored in the dark at low temperature. 1-bromododecane 97\%, 1,6-dibromohexane 96\%, potassium t-butoxide $95 \%$ were also obtained from Sigma Aldrich. The electrolyte salts used were of reagent grade: sodium dodecyl benzene sulfonate (Acros), methyl orange (Alfa Aesar) aluminon (Lancaster), xylenol orange (Fluka), tetrabutyl ammonium perchlorate (TBAP) (Aldrich).

The monomer $\mathrm{N}$-dodecylpyrrole was synthesised using a previously-reported method[10].Electrochemical polymerizations, diffusion and cyclic voltammetric 
measurements were performed in a one-compartment cell with three electrodes at room temperature with a Uniscan Potentiostat-Galvanostat P580.A calomel reference electrode, a platinum disk or wire working electrode and a stainless steel counter electrode were used for the preparation and electrochemical investigation of the properties of polypyrroles. Polymer films were deposited on platinum wire and the scanning electron micrographs were obtained with a SEM Zeiss EVO 50 instrument.

B. Cyclic voltammetry of polypyrroles films

Polypyrrole andpoly (N-dodecylpyrrole) were electrochemically prepared from aqueous and non-aqueous solutions of $0.1 \mathrm{M}$ monomer in $0.1 \mathrm{M}$ electrolytes (NaDBS, lithium perchlorate, aluminon, xylenol and methyl orange) deoxygenated by nitrogen bubbling for $15 \mathrm{~min}$. Electro polymerisation was performed on platinum wire working electrodes under potentiodynamic conditions $(-700$ to $+1200 \mathrm{mV}$ versus calomel reference electrode, scan rate, $v$ $=100 \mathrm{mV} / \mathrm{s}$ ) for the $\mathrm{CV}$ measurements.
C.In situ study of diffusion coefficient of polypyrrole films In order to study the diffusion of dopants into the polymers, films of polypyrrole and poly $(\mathrm{N}-$ dodecylpyrrole) were synthesised electrochemically. Solutions with concentrations of $0.1 \mathrm{M}$ TBAP and $0.1 \mathrm{M}$ monomer were prepared in acetonitrile $(50 \mathrm{ml})$, and polymerisation was carried outgalvanostatically $(0.1 \mathrm{~mA}$ for $10 \mathrm{~s}$ ) on a $1 \mathrm{~mm}^{2} \mathrm{Pt}$ disc electrode. The polymer films were rinsed with distilled water in order to remove any monomer left on the film surface. The electrode coated with polymer films (working electrode) were studied in three different electrolytes: $\mathrm{LiClO}_{4}, \mathrm{TMACl}$ and $\mathrm{NaDBS}$ $(0.1 \mathrm{M})$ solutions in acetonitrile which had been deoxygenated by nitrogen bubbling. For the diffusion measurements, a current of $10 \square$ A wasapplied for $1 \mathrm{~s}$; then $0 \square \mathrm{A}$ was applied for $60 \mathrm{~s}$ to provide time for the ions to return to equilibrium. By selecting the initial linear part of the graph and calculating its slope, the dopant diffusion coefficient was estimated.

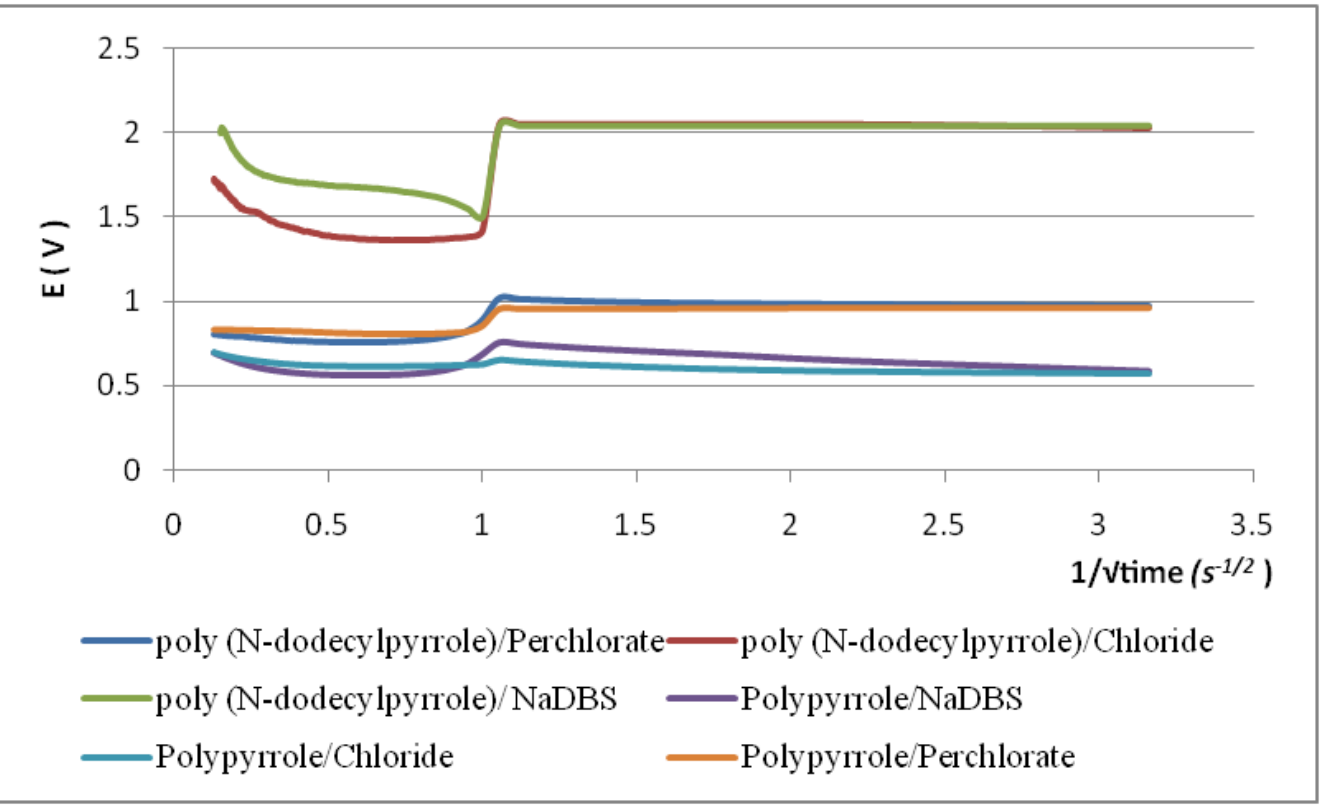

Fig. 1 Electrode potential versus(time $)^{-1 / 2}$ for poly (N-dodecylpyrrole) and polypyrrole

\section{RESULTS AND DISCUSSION}

The values of diffusion coefficients for various electro chemical cells containing $\mathrm{LiClO}_{4}, \mathrm{TMACl}$ in combinations are given in Table 1. Diffusion acetonitrile and NaDBS in water. An increase in diffusion measurements of electrochemically prepared poly $\left(\mathrm{N}-\right.$ coefficients in the order of $\mathrm{Cl}^{-}<\mathrm{ClO}_{4}^{-}$at $296.15 \mathrm{~K}$ has dodecylpyrrole) and polypyrrole films were studied in been observed.

TABLE I Ionic diffusion coefficients in poly (N-dodecylpyrrole) and polypyrrole

\begin{tabular}{|c|c|c|c|}
\hline System & $\begin{array}{c}\mathrm{D} / \mathrm{cm}^{2} \mathrm{~s}^{-1} \\
\text { Poly(pyrrole) }\end{array}$ & $\begin{array}{c}\mathrm{D} / \mathrm{cm}^{2} \mathrm{~s}^{-1} \text { Poly } \\
\text { (N-dodecylpyrrole) }\end{array}$ & Comments (or Literature Values) \\
\hline $\mathrm{LiClO}_{4} / \mathrm{CH}_{3} \mathrm{CN}$ & $1.1 \times 10^{-10}$ & $7.8 \times 10^{-11}$ & $\begin{array}{l}\text { Mirebeau[11] obtained } 5 \times 10^{-12} \mathrm{~cm}^{2} \mathrm{~s}^{-1} \text { For } \mathrm{LiClO}_{4} \\
/ \text { Poly(pyrrole) Genies and Pernaut [12] obtained } 4 \mathrm{x} \\
10^{-9} \mathrm{~cm}^{2} \mathrm{~s}^{-1} \text { for } \mathrm{LiClO}_{4}, \text { Poly(N-methylpyrrole) }\end{array}$ \\
\hline $\mathrm{TMACl} / \mathrm{CH}_{3} \mathrm{CN}$ & $1.5 \times 10^{-12}$ & $1.2 \times 10^{-12}$ & \\
\hline NaDBS/water & $2.6 \times 10^{-12}$ & $1.7 \times 10^{-12}$ & \\
\hline
\end{tabular}


The estimated values for the diffusion of $\mathrm{ClO}_{4}^{-}$in poly $\left(\mathrm{N}-\right.$ for $\mathrm{ClO}_{4}^{-}$, from $\mathrm{LiClO}_{4}$, diffusion into and out of dodecylpyrrole) and polypyrrole are polypyrrole at $298 \mathrm{~K}$.

$7.8 \times 10^{-11} \mathrm{~cm}^{2} \mathrm{~s}^{-1}$ and $1.1 \times 10^{-10} \mathrm{~cm}^{2} \mathrm{~s}^{-1}$,respectively.

As can be seen from Table 1, these values are larger than those for chloride ions. The increasing diffusion coefficient with the increase in the size of the dopant anions, suggests that counter anions used during the electro polymerisation have a great effect on the diffusion process. Since $\mathrm{ClO}_{4}^{-}$was used as the counter anion, it appears that the polymer matrix is probably more compatible with the structure of $\mathrm{ClO}_{4}^{-}$than other anions and that makes it easier for the $\mathrm{ClO}_{4}^{-}$to diffuse into the polymer. For an amorphous glassy polymer, the diffusion usually involves the hopping of molecules or ions from one region of free volume to another, which is expected to be slower (less frequent) for larger ions. Hence $\mathrm{D}\left(D B S^{-}\right)$ $\ll \mathrm{D}\left(\mathrm{ClO}_{4}^{-}\right)$, this is observed for both the polymers studied. However, we should expect D $\left(\mathrm{Cl}^{-}\right)$to be greater than $\mathrm{D}\left(\mathrm{ClO}_{4}^{-}\right)$on this principle, since the chloride ion is small.

The reason why the chloride ion diffuses more slowly may be related to the fact that its small size causes it to be more strongly polarising (i.e. stronger electrostatic attraction to the positive polar on the polymer backbone).These results can be compared with those of Mirebeau [12] who obtained adiffusion coefficient of $5 \times 10^{-12} \mathrm{~cm}^{2} \mathrm{~s}^{-1}$

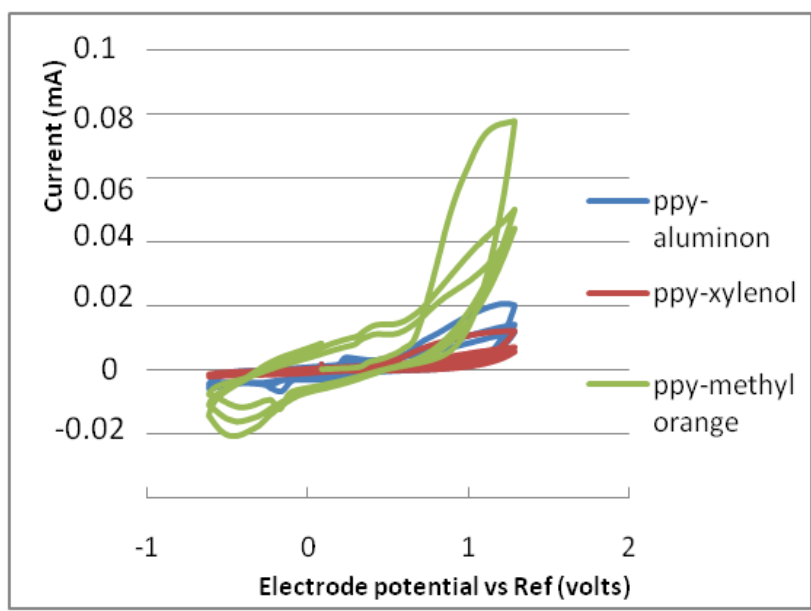

Fig. 2 Cyclic voltammetry curves forpolypyrrole in aluminon, xylenol orange and methyl orange in water. Scan rate is $100 \mathrm{mV} / \mathrm{s}$.

The voltammogram of polypyrrole in the presence of three large organic dye molecules revealed that methyl orange had the largest redox activity in comparison to aluminon and xylenol orange. It is apparent that the smaller size of methyl orange has a great effect the redox activity (Fig. 2).
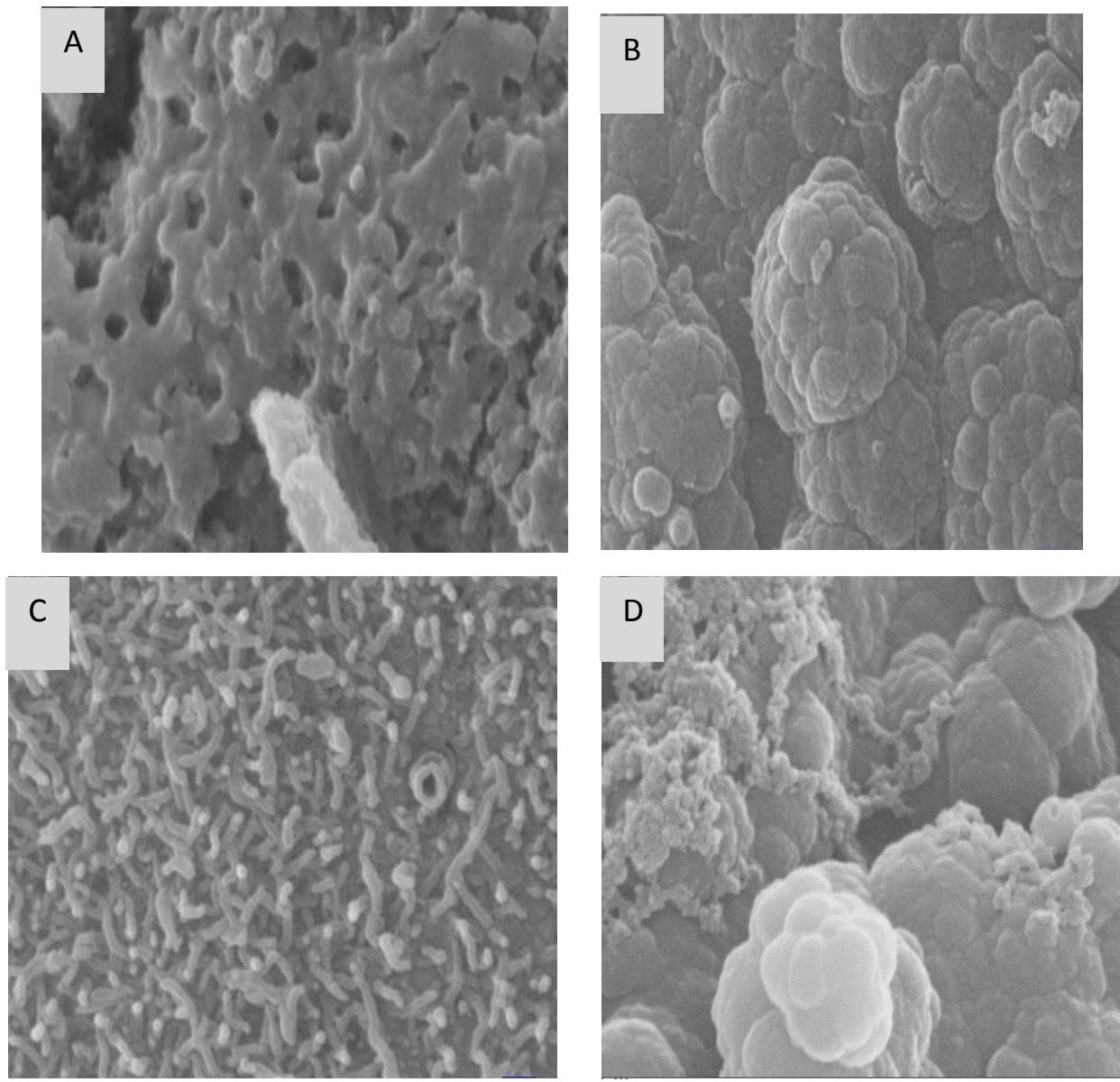

Fig. 3. SEM photos of poly (N-dodecylpyrrole) and polypyrrole $(200 \mathrm{~nm})$

A: polypyrrole in alumin on dye, B: polypyrrole in $\mathrm{LiClO}_{4}, \mathrm{C}$ : polypyrrole in 3,5-dinitrosalicylic acid,

D: poly (N-dodecylpyrrole) in TBAP 
Figs. 3 A and C show SEM images of polypyrrole films electrochemically synthesized on the platinum electrode in the presence of aluminon and 3,5-dinitrosalicylic acid respectively. It was found from the experimental results that in the presence of aluminon a porous structure can be obtained. Aluminon, which contains three negative sites, acts as a template during polymerisation and induces an increase of the empty spaces in the polymer structure. Synthesis of polypyrrole in the presence of 3,5dinitrosalicylic acid revealed a vermicular morphology. Such porous structure can be seen in the work of Yang et al; they obtained polypyrrole nanotubes in the presence of methyl orange. Methyl orange plays a role of active sites for the growth of polypyrrole [12].

Fig. 3D shows the SEM micrograph of poly (Ndodecylpyrrole) electrochemically synthesised on the platinum working electrode. This photo shows a more complex morphology rather than the cauliflower-like appearance of polypyrrole (Fig. 3 B). Since the oxidation potential of $\mathrm{N}$-dodecylpyrrole monomer is higher than pyrrole monomer, it is possible that over oxidation happens and creates such a complex structure.

\section{CONCLUSION}

A wide variety of morphologies were obtained, depending on the electrolyte and on the conditions used. The diffusion coefficients of several dopant counter-ions were estimated using a galvanostatic pulse technique. All the polymers were synthesised using a per chlorate salt electrolyte, which gave a relatively smooth, low-area surface. It was found that the diffusion coefficient for $\mathrm{ClO}_{4}^{-}$was much greater than for $\mathrm{BBS}^{-}$, which was attributed to the sizes of these two ions. However the smaller $\mathrm{Cl}^{-}$ion had a very low diffusion coefficient. This may be due to the more strongly polarising effect of the small ion, causing it to be trapped by the electrostatic field of the positive polarons. Alternatively the internal morphology of the $\mathrm{ClO}_{4}^{-}$polymer may contain holes or channels that are especially compatible with the $\mathrm{ClO}_{4}^{-}$ dopant ions, and allow them to move very easily in the polymer film.

\section{REFERENCES}

[1] G. Wallace, G. M. Spinks, L. Kane-Maguire, P. Griffith, Conductive Electro active Polymers, Third Edition, Taylor \& Francis , 2009, 59-65.

[2] T. A. Skotheim and J. R. Reynolds, Conjugated Polymers, Theory, Synthesis, Properties, And Characterization, Third edition, Taylor \& Francis, 2006, 8.1-8.8.

[3] S. Geetha, C. Rao, M. Vijayan, D.C. Trivedi, Bio sensing and drug delivery by polypyrrole, Analytica Chimica Acta, 2006, 119-125.

[4] D. J. Walton, C. E. Hall and A. Chyla, Characterization of Poly(pyrro1e)s by Cyclic Voltammetry, Analyst, 1992, 1305-1311.

[5] H. Zhao, W.E. Price, G.G. Wallace, Synthesis, characterisation and transport properties of layered conducting electroactivepolypyrrole membranes, Journal of Membrane Science, 1998, 161-172.

[6] S. Sadki, P. Schottland, N. Brodie and G. Sabouraud, The mechanisms of pyrroleelectropolymerization, Chem. Soc, 2000, 283-293.

[7] T. Raudsepp, M. Marandi, T. Tamm, V. Sammelselg, J. Tamm, Study of the factors determining the mobility of ions in the polypyrrole films doped with aromatic sulfonate anions, Electrochimica Acta, 2008, 3828-3835.
[8] P. J. S. Foot, F. Mohammed, P. D. Calvert and N. C. Billingham, Diffusion in Conducting Polymers, J. Phys, (D): Appl. Phys, 1987, 1354-1360.

[9] D. A. Winn, J. Shemilt, B.C.H. Steele, Titanium disulphide: a solid solution electrode for sodium and lithium, Mater. Res. Bull, 1976, 559-566.

[10] P. Ibison, P. J. S. Foot, J.W. Brown, Preparation and characterization of polypyrrole, $\mathrm{N}$-substituted with liquid crystalline moieties, Synth. Met. 1996, 297-300.

[11] F. Mohammad, Comparative studies on diffusion behaviour of electrochemically prepared polythiophene and polypyrrole: effect of ionic size of dopant, Synthetic Metals, 1999, 149-154.

[12] X. Yang, T. Dai, Z. Zhu, Yun Lu.Electrochemical synthesis of functional polypyrrole nanotubes via a self-assembly process, Polymer48, 2007, 4021-4027. 